\title{
Utilizing Maxwell-Boltzmann Statistic to Predict Dynamic Trend Lines and Percentage of Price Changes
}

\author{
John P. Kaunang \\ Indonesian Institute of Sciences, (LIPI) \\ Research Centre for Physics (P2 Fisika) \\ PUSPIPTEK, Serpong, Indonesia \\ Emails: john.p@ui.ac.id, john.p@lipi.go.id, \\ johnpkaunang@yahoo.fr, \\ johnpoerwadikaunang@gmail.com
}

\author{
Ferdinand D. Saragih \\ University of Indonesia \\ Faculty of Administration Sciences (FIA). \\ Depok, Indonesia \\ Bernardus Yuliarto Nugroho \\ University of Indonesia \\ Faculty of Administration Sciences (FIA) \\ Depok, Indonesia
}

\begin{abstract}
In this paper, we've investigated the involvement of closing volumes on closing prices in order to achieve a better trend lines indicator. MaxwellBoltzmann distribution physical statistic law and its probabilistic formula were utilyzed to analyze the dynamic trend lines and deviation percentage of price changes, where closing prices and volumes were used as variables indeed. Many traders ignore volumes; however, there is a huge number of information in it, particularly in volume of closing prices. This Maxwell-Boltzmann distribution law could be manipulated to predict shares dynamic trend lines in Indonesian Stock Exchanges market. Since these analysis could be utilized to predict the dynamic trend lines on bullish or bearish market, and percentage of price changes, than; 1 . We are going to have the comparison of the dynamic trend line changes (uptrend or down trend) by utilizing Maxwell-Boltzmann distribution law, and compare them to the George Lane stochastic oscillator formula. The result of the comparison percentage was 72,14 to 42,26, (72.14 \% right for Maxwell-Boltzmann, and 42\% right for George Lane stochastic oscillator). 2. On the other hand, the utilization of Maxwell-Boltzmann probability, gains percentage of minimum price changes around \pm 0 to 3.59 percent (minimum deviation), and (maximum deviation) around \pm 0 to 4,67 percent, in Indonesian Stock Exchanges market.
\end{abstract}

Keywords-Maxwell-Boltzmann statistic Distribution, Maxwell-Boltzmann probability, closing volume, uptrend, bullish, downtrend, bearish, percentage price change

\section{INTRODUCTION}

Many traders around the word say:'Trading like a microcosm of life". In trading, as usually as in life, we pursue and chase value. In both trading and life, we manage the risk of those pursuits' loss opportunities and realize losses. Our personal and professional success will be determined by how we seek value and manage the associate risk.

A widely accepted idea in financial management theory is that time series of asset prices are unpredictable. This main idea is presume a cornerstone of the description of price dynamics as stochastic process. Since few decades ago, it has been understood in physical sciences that unpredictable time series and stochastic process are not as equally as the same, or synonymous. Specially, which is chaos theory has shown that unpredictable time series to be able to arise from deterministic nonlinear systems. Afterword, the results gained/obtained in the study of physical and biological systems enhance and triggered an interest in economic systems, and theoretical, moreover in empirical studies have investigated, whether the time evolution of asset price changes in financial market naturally, might indeed be due to underlying nonlinear deterministic dynamics of a (limited) number of variables.

Many financial markets over the world expose/exhibit several of the properties that characterize complex systems. They are nonlinearity in presence of feedback. Until now, in financial market, the governing rules are rather stable and time evolution of the system is continuously monitored as well. It is now possible for anyone to develop models and to test their accuracy and analytical power using available data, since large databases exist even for high-frequency of data.

Date back to $1960 \mathrm{~s}$, a huge number of empirical investigations have been devoted to testing the efficient market hypothesis. However, in the great majority of these empirical studies, the time correlation in between price changes has been found to be negligibly small or vanish, and those studies, were supporting the efficient market hypothesis. Meanwhile, we try to add volume variable and mixed it with price variable into Maxwell-Boltzmann formulae's, in order to accomplish for predicting the dynamic trend lines of shares, and percentage of price changes, instead of using information present in additional time series (micro economic data's) such 
as earning/price ratios, dividend yield, and term-structure variables to predict the dynamic trend lines and percentage price changes of shares.

In a closed economic system, money is conserved as in Boltzmann distribution law, where molecules of gases are conserved. Shares or stocks could be seen as molecules or particles of gases. Molecules of gases all the time move around, unpredictably in any state of level and perceive a certain level of energy. If molecules of gases are heated, they'll move upward unpredictably and occupy the higher level of energy. Conversely, if those gases are cooled down at a lower temperature, they'll move downward to occupy a lower level of energy.

In financial market, volumes are available in total volume transactions, at the end of the day transactions only. The time series of data is shown on few days, few month or few years. However, if someone might count and manages volume amount of each transaction by utilizing of MaxwellBoltzmann statistic distribution law, than he or she might predict the volume amount of open prices, highest, lowest and closing prices, in the time series of data's $\left(\mathrm{n}_{\mathrm{i}}\right)$. Meanwhile, it can be assumed alike molecules of gases, they'll occupy certain state of energies/prices level $\left(\varepsilon_{\mathrm{i}}\right)$. Finally, both of them (volumes and prices) could be managed by utilizing MaxwellBoltzmann statistic distribution law, then, it will give us the momentum of dynamic trend lines. In other side, if we utilized Maxwell-Boltzmann probabilistic formula's it will give us the percentage of price changes of shares.

The law of Maxwell-Boltzmann (MB) statistic distribution is

$$
n_{i}=\frac{N}{Z} g_{i} e^{-\beta \varepsilon_{i}}
$$

, and can be utilized to predict the dynamic trend lines of shares [1]. By managing and developing Maxwell-Boltzmann probability formula of

$$
P=\prod_{i=1}^{N} \frac{g_{i}{ }^{n}}{n_{i} !}
$$

, we might obtain the percentage price changes of shares [1].

\section{METHOD}

\section{A. Samples and data}

The times series shares data of Indonesian Stock Exchanges are available at www.idx.co.id. In this research, 50 stock samples from around 556 listed companies in Indonesian Stock Exchanges (Idx) market were chosen as purposive samples. Entire data's are tabulated for 22 weeks continuously as ordinary as it prices and total volume in its original form (start from $2^{\text {nd }}$ January 2013 to $13^{\text {th }}$ May 2013). By utilizing Maxwell-Boltzmann distribution statistic formula, each of stock series price data's were calculated, tabulated and converts to the form of volume by price data's. Afterward, these collected volume by price data's are stored into an excel software program as a fast line trend data's $(\% \mathrm{~K}$, tabulated in excel formula formatted data's). On the other hand, the 3 day consecutive closing volume data's ( $\%$ D, or lagging line) accordingly summed and averaged in series, to avail as a slow line (lagging line) data's, and store them into the excel software as well. Finally the graph of Maxwell-Boltzmann distribution of volume by price analysis could be drawn by utilizing excel formula program, and it will appear automatically if we manage the computer to draw them. The result from each regression of a fast trend line $(\% \mathrm{~K})$ cross over a slow line $(\%$ D), it will show, an uptrend or down trend market (Bullish or bearish market). The uptrend or down trend points, which's given with the right signals were put, counted and stored as the right points, and then they are chosen as the right samples and stored into the SPSS 22 software, then to be calculated next. The same manner was treated to the George Lane Oscillator Stochastic formula as well.

\section{B. Hypotheses Development and Theses Hypotheses}

Using of Maxwell-Boltzmann statistic theory. Volume amount of open prices, highest, lowest and closing prices, in the time series of data $\left(\mathrm{n}_{\mathrm{i}}\right)$, they described and could be assumed alike molecules of gases. They'll occupy a certain state of energy level/price level $\left(\varepsilon_{\mathrm{i}}\right)$. Volumes and closing prices in series value on the end of trading day, if they were managed by utilizing Maxwell-B0ltzmann statistic distribution law, it could give us a momentum of dynamic trend lines. In the other hand, if we utilized Maxwell-Boltzmann probabilistic formula's it will give us the percentage of price changes of shares as well.

\section{Thesis hypothesis:}

$\mathbf{H}_{\mathbf{0}}$ : Maxwell-Boltzmann statistic distribution law and probability formula could be utilized as proxy appliances to predict the IDX market dynamics trend lines and percentage of price changes.

$\mathbf{H}_{\mathbf{a}}$ : Maxwell-Boltzmann statistic distribution law and probability formula could not be utilized as proxy appliances to predict the IDX market dynamics trend lines and percentage of price changes.

To find each of partial volume (Open, Highest, Lowest, Close), we apply the law of Maxwell-Boltzmann distribution formula above as:

$$
n_{i}=\frac{N}{Z} g_{i} e^{-\beta \varepsilon_{i}}
$$

Where:

$n_{i}=$ volume for (open, highest, lowest or close)

$N=$ Total volume of stock transaction at the end of the day (EOD).

$\mathrm{Z}=$ Partition function of Maxwell-Boltzmann 
$k_{b}=$ Boltzmann constant

$\mathrm{T}=$ Effective temperature, in this formula could be assume as work activity $\infty 1,[11]$.

$e=$ Exponential

$\varepsilon_{i}=$ Stock prices of (open, highest, lowest or close)

In this case, $\beta$ can be taken as equal to approximately as 1 , [11].

$$
Z=\sum_{i=1}^{n} g_{i} e^{-\beta \varepsilon_{i}}
$$

For instant, the calculation result of closing volume on closing price, [look at column volume (I2), \% K(n $\left.\mathbf{n}_{4}\right)$ in Astra Agro Lestari Tbk (AALI) stock], which is utilizing MaxwellBoltzmann distribution formula, and shown in an excel table, as table I below:

TABLE I. THE AALI SHARE 30 DAYS DATA, SINCE 2 JANUARY UNTIL 13 FEBRUARY 2013:

\begin{tabular}{|c|c|c|c|c|c|c|c|c|}
\hline \multirow[b]{2}{*}{ No } & \multicolumn{8}{|c|}{$\begin{array}{l}\text { The AALI data utilized to draw a chart of closing volumes on } \\
\text { closing prices }\end{array}$} \\
\hline & Date & $\begin{array}{c}\text { Open } \\
\varepsilon_{1} \\
(D 2)\end{array}$ & $\begin{array}{c}\text { High } \\
\varepsilon_{2} \\
(E 2)\end{array}$ & $\begin{array}{c}\text { Low } \\
\varepsilon_{3} \\
(F 2)\end{array}$ & $\begin{array}{c}\text { Close } \\
\varepsilon_{4} \\
(G 2)\end{array}$ & $\begin{array}{c}\text { Vol } \\
N \\
(H 2)\end{array}$ & $\begin{array}{c}\text { Vol } \\
\text { close } \\
\text { (I2) \% } \\
K\left(n_{4}\right)\end{array}$ & $\begin{array}{l}\mathrm{Vol} \\
\% \mathrm{D}\end{array}$ \\
\hline 1. & $\begin{array}{c}02 \\
\text { Jan } \\
13\end{array}$ & $\begin{array}{c}19.70 \\
0\end{array}$ & $\begin{array}{c}20.20 \\
0\end{array}$ & $\begin{array}{c}19.70 \\
0\end{array}$ & $\begin{array}{c}20.05 \\
0\end{array}$ & $\begin{array}{c}1.61 \\
7.50 \\
0\end{array}$ & 39.88 & \\
\hline 2. & $\begin{array}{l}03 \mathrm{Ja} \\
\mathrm{n} 13\end{array}$ & $\begin{array}{c}20.45 \\
0\end{array}$ & $\begin{array}{c}20.85 \\
0\end{array}$ & $\begin{array}{c}20.15 \\
0\end{array}$ & $\begin{array}{c}20.70 \\
0\end{array}$ & $\begin{array}{c}2.05 \\
7.50 \\
0\end{array}$ & 50.59 & \\
\hline 3. & $\begin{array}{c}04 \\
\text { Jan } \\
13 \\
\end{array}$ & $\begin{array}{c}20.30 \\
0\end{array}$ & $\begin{array}{c}20.65 \\
0\end{array}$ & $\begin{array}{c}20.05 \\
0\end{array}$ & $\begin{array}{c}20.60 \\
0\end{array}$ & $\begin{array}{c}1.32 \\
1.00 \\
0\end{array}$ & 32.36 & $\begin{array}{r}30.1 \\
578\end{array}$ \\
\hline 4. & $\begin{array}{c}07 \\
\text { Jan } \\
13\end{array}$ & 20200 & 20850 & 20200 & 20650 & $\begin{array}{c}8570 \\
00\end{array}$ & 21.08 & $\begin{array}{r}34.6 \\
767\end{array}$ \\
\hline 5. & $\begin{array}{c}08 \\
\text { Jan } \\
13\end{array}$ & 20550 & 20700 & 20250 & 20450 & $\begin{array}{c}7245 \\
00\end{array}$ & 18.12 & $\begin{array}{r}23.8 \\
534\end{array}$ \\
\hline 6 & $\begin{array}{l}\text { 09Ja } \\
\mathrm{n} 13\end{array}$ & 20450 & 20450 & 20050 & 20200 & $\begin{array}{c}9280 \\
00\end{array}$ & 23.46 & $\begin{array}{r}20.8 \\
867\end{array}$ \\
\hline & $\begin{array}{l}\text { Unti } \\
\text { l. }\end{array}$ & & & & & & & \\
\hline 27. & $\begin{array}{c}08 \\
\text { Feb } \\
13\end{array}$ & 18900 & 18950 & 18850 & 18900 & $\begin{array}{c}1425 \\
000\end{array}$ & 35.46 & $\begin{array}{l}36.8 \\
600\end{array}$ \\
\hline 28. & $\begin{array}{c}11 \\
\text { Feb } \\
13\end{array}$ & 18900 & 18900 & 18800 & 18850 & $\begin{array}{c}5610 \\
00\end{array}$ & 14.08 & $\begin{array}{l}21.1 \\
567\end{array}$ \\
\hline 29. & $\begin{array}{c}12 \\
\mathrm{Feb}\end{array}$ & 18850 & 19000 & 18800 & 18900 & $\begin{array}{c}1041 \\
000\end{array}$ & 25.81 & $\begin{array}{l}25.1 \\
167\end{array}$ \\
\hline
\end{tabular}

\begin{tabular}{|c|c|c|c|c|c|c|c|c|}
\hline \multirow{2}{*}{} & \multicolumn{7}{|c|}{ The AALI data utilized to draw a chart of closing volumes on } \\
closing prices
\end{tabular}

1. $n_{4}=(\mathrm{H} 3) /\left(2.71828^{\wedge}-(\mathrm{D} 3)+2.71828^{\wedge}-(\mathrm{E} 3)+2.71828^{\wedge}-\right.$ $\left.(\mathrm{F} 3)+2.71828^{\wedge}-(\mathrm{G} 3)\right)^{*}\left(2.71828^{\wedge}-(\mathrm{G} 3)\right)$. This closing volume on closing price equation by excel is equal to Maxwell-Boltzmann (MB) distribution formula as bellow:

$$
n_{i}=\frac{N}{Z} g_{i} e^{-\beta \varepsilon_{i}}
$$

$\mathrm{Z}=\left(2.71828^{\wedge}-(\mathrm{D} 3)+2.71828^{\wedge}-(\mathrm{E} 3)+2.71828^{\wedge}-\right.$ (F3)+2.71828^-(G3)) (Partition function)

State level, $g_{\mathrm{i}}=1$ (assume as equal to 1 , because of stock probability to move upward or downward, has the same chance or probability)

2.

$$
\begin{gathered}
\% \mathrm{D}=(\mathrm{I} 3+\mathrm{I} 4+\mathrm{I} 5) / 3 \\
(\text { Lagging line })
\end{gathered}
$$

Where:

$n_{4}=$ Volume on closing price

$\mathrm{H} 3=\mathrm{N}$ (total volume transaction in the End Of Day, EOD);

D3 $=$ Open price

E3 $=$ Highest price

F3 = Lowest price

$\mathrm{G} 3=$ Close Price

e (exponential number $)=2.71828$;

$\wedge$ = Power;

$*=$ Times.

$(\mathrm{I} 3+\mathrm{I} 4+\mathrm{I} 5) / 3=($ Volume Close day $1+$ Volume Close day $2+$ Volume close day 3 ) over 3 Days $=$ Averaging 3 days closing volume value or $\% \mathrm{D}$ (Lagging line).

The result of stock dynamic trend line chart (closing volume by closing price chart), on the AALI (Astra Agro Lestari Tbk.) Company stock chart I could be seen below. 
Secondly, the test also did to prove, whether the probability of Maxwell-Boltzmann formula which has been utilized to accomplish the percentage of price changes has demonstrate itself, whether it could be represent as a proxy instrument in Idx market as well or not.

\section{A. The Z test for Maxwell-Boltzmann statistic distribution law}

The purpose of $\mathrm{Z}$ test for Maxwell-Boltzmann statistic distribution law in this research is intended to compare in between the results did by Maxwell-Boltzmann statistic and by George Lane stochastic oscillator. We chosed randomly the Maxwell-Boltzmann and the George L. stocastic oscillator calculation results in between ( 50 x 22 weeks) purposive samples, which were counted beginning from 2 January 2013 until 13 May 2013 (22 weeks). The result was managed by SPSS 22 software, and can be seen in (Tabel II)

When the diamond line (blue color) crossed the square line (red color) upward, it shows that, in this time the trend is beginning to move upward or uptrend (bullish market). When the fast line or diamond line beginning to move cross downward to the square line, in this situation, the trend is beginning to go down or in downtrend, and at this time the market will be experiencing a bearish market.

We did the same manner to the George Lane stochastic oscillator for all of 50 purposive sample shares as well, in order to acquire the calculation results and graphs as above, and then compare it to the Maxwell-Boltzmann distribution formula result.

The Maxwell-Boltzmann probability formula, which we are going to utilize to count the percentage price changes, is

$$
\frac{P^{\prime}}{P}=\prod_{i=1}^{N} \frac{n_{i} !}{n_{i}^{\prime} !}
$$

Where:

$P^{\prime}=$ Probability after shares volume has changes $(\mathrm{t}+1)$

(beforehand)

$P=$ Probability of shares volume previously.

$N=$ Total volume by price change.

$n_{i}, !=$ Factorial Total volume of transaction beforehand

$n_{i} !=$ Factorial Total volume previously.

\section{RESULT}

Before we get the result, first of all, we are going to examine whether the result of Maxwell-Boltzmann distribution law in order to achieve for a good predictor dynamic trend lines in Idx market finally proved itself.

TABLE II. Z-TEST FOR MAXWELL-BOLTZMANN STATISTIC

\begin{tabular}{|c|c|r|r|c|}
\hline \multirow{2}{*}{ Group } & \multicolumn{3}{|c|}{ Group Statistics } \\
\cline { 2 - 5 } & $N$ & Mean & $\begin{array}{c}\text { Std. } \\
\text { Deviation }\end{array}$ & $\begin{array}{c}\text { Std. Error } \\
\text { Mean }\end{array}$ \\
\hline $\begin{array}{c}\text { Predictor: } \\
\text { Stochastic } \\
\text { oscillator }\end{array}$ & 50 & $\begin{array}{r}42.26 \\
00\end{array}$ & 13.08342 & 1.85028 \\
\hline $\begin{array}{c}\text { Max- } \\
\text { Boltzmann } \\
\text { oscillator }\end{array}$ & 50 & $\begin{array}{r}72.14 \\
00\end{array}$ & 11.19769 & 1.58359 \\
\hline \multicolumn{2}{|c|}{ Source: SPSS 22 software calculation } & &
\end{tabular}

According to table 2, the correct average results have been done by predictor trend line George Lane Stochastic Oscillator was $42.26 \%$, while the right average predicted persentage did by Maxwell-Boltzmann Oscillator was $72.14 \%$.

\section{B. Independent samples test}

The main idea behind an independent $t$ test for the two samples is to search, whether there are an equality or difference of means between those two populations or not. The result can be seen in table III below, 


$$
\frac{P^{\prime}}{P}=\prod_{i=1}^{N} \frac{n_{i} !}{n_{i}^{\prime} !}
$$

Table III INDEPENDENT SAMPLE

\begin{tabular}{|c|c|c|c|c|c|c|c|c|c|}
\hline \multirow{2}{*}{ Group } & \multicolumn{4}{|c|}{$\begin{array}{l}\text { Levine's Test for Equality } \\
\text { of Variances }\end{array}$} & \multirow[t]{2}{*}{$\begin{array}{l}\text { Sig } \\
.(2- \\
\text { tail } \\
\text { ed) }\end{array}$} & \multirow[t]{2}{*}{$\begin{array}{l}\text { Mea } \\
n \\
\text { Diffe } \\
\text { renc } \\
e\end{array}$} & \multirow{2}{*}{$\begin{array}{c}\text { Std. } \\
\text { Erro } \\
r \\
\text { Diffe } \\
\text { renc } \\
e \\
\end{array}$} & \multicolumn{2}{|c|}{$\begin{array}{c}95 \% \\
\text { Confidence } \\
\text { Interval of the } \\
\text { Difference }\end{array}$} \\
\hline & $F$ & Sig & $T$ & $d f$ & & & & $\begin{array}{l}\text { Low } \\
\text { er }\end{array}$ & Upper \\
\hline $\begin{array}{c}\text { Predic } \\
\text { tor }\end{array}$ & & & & & & & & & \\
\hline $\begin{array}{c}\text { G. } \\
\text { Lane } \\
\text { Stoc } \\
\text { hasti } \\
\quad c\end{array}$ & $\begin{array}{c}2 . \\
39 \\
4\end{array}$ & $\begin{array}{l}0.1 \\
25\end{array}$ & $\begin{array}{c}- \\
12.2 \\
69\end{array}$ & 98 & $\begin{array}{l}0.0 \\
00\end{array}$ & $\begin{array}{c}- \\
29.8 \\
8000\end{array}$ & $\begin{array}{l}2.43 \\
542\end{array}$ & $\begin{array}{c}- \\
34.7 \\
1302\end{array}$ & $\begin{array}{c}- \\
25.04 \\
698\end{array}$ \\
\hline $\begin{array}{c}\text { Max- } \\
\text { Boltzm } \\
\text { ann } \\
\text { osci }\end{array}$ & & & $\begin{array}{r}- \\
12 . \\
26 \\
9\end{array}$ & $\begin{array}{r}95 . \\
71 \\
8\end{array}$ & $\begin{array}{l}0 . \\
00 \\
0\end{array}$ & $\begin{array}{r}29 . \\
29 . \\
00 \\
0\end{array}$ & $\begin{array}{r}2.4 \\
35 \\
42\end{array}$ & $\begin{array}{r}- \\
34 . \\
71 \\
30 \\
2\end{array}$ & $\begin{array}{r}- \\
25.0 \\
455 \\
4\end{array}$ \\
\hline
\end{tabular}

\section{Analysis of equivariance}

It is important to search whether in between the two groups, it is an equality of variance or not?

\section{Hypothesis:}

$\mathbf{H}_{0}=$ The two variance populations which are utilized to predict the dynamic trend lines, are indentical. (the data's which's utilized to predict the dynamic trend lines are not significantly different)

$\mathbf{H}_{1}=$ The two variance populations which are utilized to predict the dynamic trend lines are not indentical. (the data's which's utilized to predict dynamic trend lines are significantly different).

\section{Decission:}

According to F calculation, and the Leven's test, which shown that the equal variance assumed was 2,394, accompanied by the probability of 0.125 . Since the probability was $0.125>0.05$, than $\mathrm{H}_{0}$ is accepted. It can be said, that the two population variances are synonymous to predict the dynamic trend lines in the Idx market.

\section{Persentage of Price changes by Maxwell-Boltzmann Probability formula.}

Utilyzing a formula (6) above, we applied it to calculated precentage of price changes. $P$ is equal to closing volume on closing price probability at previous state/ original state level $(t) . P^{\prime}$ is the probability of closing volume on closing price, in advance $(t+1)$.

$$
P=\prod_{i=1}^{N} \frac{g_{i}^{n_{i}}}{n_{i} !} \quad P^{\prime}=\prod_{i=1}^{N} \frac{g_{i}^{n_{i}^{\prime}}}{n_{i}^{\prime} !} \longrightarrow
$$

Where $g=g_{1}=g_{2}=g_{3} \ldots \ldots g_{i} \infty 1$, are the state level of prices. Since prices could be able to move from one state to another state (upward or downward, increase or decrease) hence, they have the same probability to move upward or to go downward, than g's equal to one.

$N=$ Total volume by price changes

$n_{i} !=$ Factorial volume by price value before change or previously (t)

$n_{i}^{\prime} !=$ Factorial volume by price changes beforehand (in advance)/has changed $(t+1)$.

We chose 9 companies (BSDE, BBCA, GGRM, INDF, ISAT, JSMR, PTBA, SMGR, and TLKM) as samples from 50 purposive samples (as the population) to calculate the probability of percentage price changes. For instant in AALI closing price change on 8 January 2013 to 9 January 2013 was:

$\frac{P^{\prime}}{P}=\frac{18 !}{23 !}=2.4765470989727 \times 10^{-7} x\left(10^{7}\right) x(\%)=2.47 \%$

$\left(10^{7}\right)$ number is utilized to normalize the value.

After calculated them, then we began to compile these data's into SPSS 22 software. The percentages of price changes results are shown as in the table IV below.

TABLE IV PERCENTAGE OF PRICE CHANGE BY MAXWELLBOLTMANN PROBABILITY FORMULA

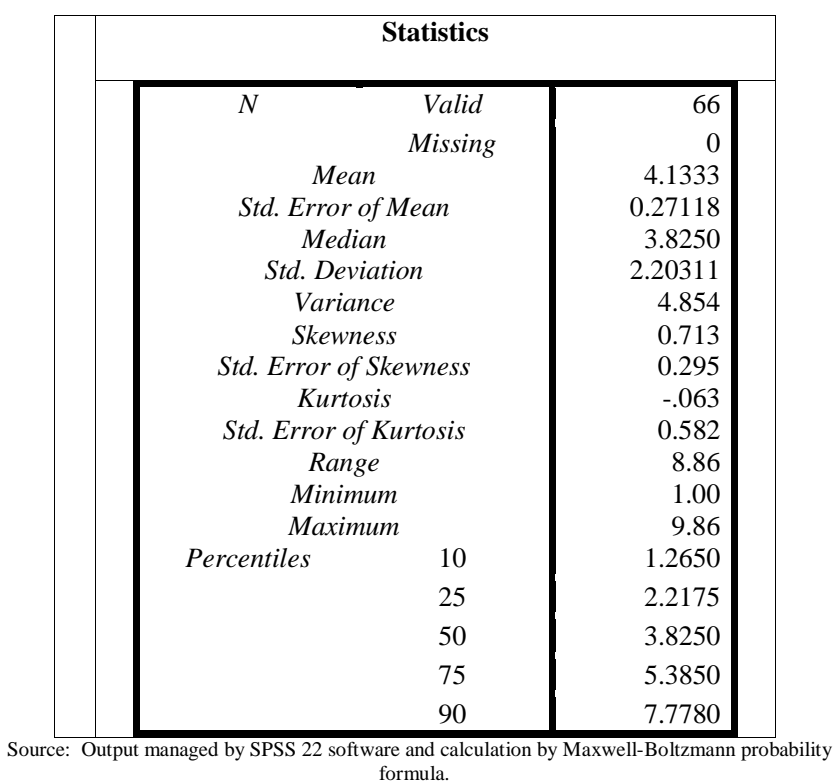


Total numbers of valid data's were $66 \mathrm{~s}$, without missing data's. All of the data's were processed. The mean result is $4,13 \%$. Standard Error of Mean is $0,271 \%$. The original standard significant value given by SPSS 22 software is $95 \%$. An average predictability formula is:

\section{Average \pm ( $z$ calculated $x$ S.E Mean/ Standard Error of Mean)}

According to the $\mathrm{Z}$ table with the value signification of $95 \%$, and the degree of freedom, $\mathrm{df}=(66-1)=65$, we have the $\mathrm{Z}$ calculated result of 1,98 or $\infty 2$, hence:

Average percentage of price changes by utilizing MB probability formula (deviation) is:

\section{$4,13 \% \pm(2 \times 0,271 \%)=$ upward/downward from the regression(cross over) of a trend line point, \pm (Deviation minimum 0 - 3,59\% up to maximum 0 - 4,67\%).}

Now we apply them into, an -in the sample test-. The purpose of this test is to observe whether MB probability results are going to accomplished and can be utilized to analyze the percentage of price changes or not. How much the percentage deviation is gained? However, we are going to choose the share of AALI Company as in the sample test. The right consecutive change points are chosen, and counted by MB probability formula. As the result, the deviation percentage price changes were still following the minimum range deviation of 0 to $3.59 \%$. This deviation percentage price change results can be seen in Table $\mathrm{V}$, below.

\section{TABLE V. IN THE SAMPLE TEST FOR DEVIATION PERSENTAGE OF} PRICE CHANGES DURING REGRESSION STATE

\begin{tabular}{|c|c|c|c|}
\hline \multirow[b]{2}{*}{ no } & \multicolumn{3}{|c|}{$\begin{array}{l}\text { AALI (Astra Agro Lestari Indonesia) Share, from } 3 \text { January until } \\
\qquad 12 \text { February 2013, \% price changes }\end{array}$} \\
\hline & Date & Close, $\varepsilon_{4}$ & Price Chg, \% \\
\hline 1. & 03Jan 2013 & 20.700 & \\
\hline 2. & 04 Jan 2013 & 20.600 & 0,49 \\
\hline 3. & 08 Jan 2013 & 20450 & \\
\hline 4. & 09 Jan 2013 & 20200 & 1.23 \\
\hline 5. & 10 Jan 2013 & 19550 & 3.22 \\
\hline 6. & 11 Jan 2013 & 19550 & \\
\hline 7. & 14 Jan 2013 & 19800 & 1.28 \\
\hline 8. & 17 Jan 2013 & 19100 & \\
\hline 9. & 18 Jan 2013 & 19250 & 0.79 \\
\hline 10. & 21 Jan 2013 & 19150 & \\
\hline 11. & 22 Jan 2013 & 19300 & 0.79 \\
\hline 12. & 23 Jan 2013 & 19250 & 0.26 \\
\hline 13. & 25 jan 2013 & 19350 & \\
\hline 14. & 28 jan 2013 & 19250 & 0.52 \\
\hline 15. & 29 Jan 2013 & 19000 & 1.3 \\
\hline 16. & 30 Jan 2013 & 18950 & 0.27 \\
\hline 17. & 31 Jan 2013 & 18850 & 0.53 \\
\hline 18. & 04 Feb 2013 & 19150 & \\
\hline 19. & 05 Feb 2013 & 19100 & 0.27 \\
\hline 20. & 06 Feb 2013 & 19000 & 0.53 \\
\hline 21. & 07 Feb 2013 & 18900 & 0.53 \\
\hline 22. & 08 Feb 2013 & 18900 & \\
\hline 23. & 11 Feb 2013 & 18850 & 0.27 \\
\hline 24. & 12 Feb 2013 & 18900 & 0.27 \\
\hline
\end{tabular}

For the out of sample test of deviation percentage of price changes, we have chosen 10 samples of stocks to be analyzed. However, the deviation percentages of price change results were still in their consistency following the MaxwellBoltzmann probability formula. The maximum deviation values of percentage of price changes were 0 to $4.67 \%$. Which could be seen in table VI, below.

TABLE VI. OUT OF SAMPLE TEST FOR PERCENTAGE PRICE CHANGES

\begin{tabular}{|c|c|c|c|c|c|}
\hline \multirow[b]{2}{*}{ no } & \multicolumn{5}{|c|}{ Percentage price changes } \\
\hline & Date & Code & Close, $\varepsilon_{4}$ & $\begin{array}{c}\text { Price } \\
\text { Chg }\end{array}$ & $\begin{array}{c}\text { Price Chg, } \\
\%\end{array}$ \\
\hline 1. & $6 / 15 / 2017$ & AALI & 14,300 & 75 & 0.53 \\
\hline 2. & $6 / 15 / 2017$ & ASRI & 322.00 & -0.2 & -0.07 \\
\hline 3. & $6 / 14 / 2017$ & BBCA & 17,975 & 100 & 0.57 \\
\hline 4. & $6 / 14 / 2017$ & BBRI & 14,850 & 375 & 2.6 \\
\hline 5. & $6 / 14 / 2017$ & ADRO & 1,660 & 60 & 3.75 \\
\hline 6. & $6 / 14 / 2017$ & AKRA & 6,575 & 175 & 2.74 \\
\hline 7. & $6 / 14 / 2017$ & BBRI & 14,625 & 250 & 1.74 \\
\hline 8. & $6 / 12 / 2017$ & UNVR & 47,200 & -350 & -0.76 \\
\hline 9. & $6 / 12 / 2017$ & UNTR & 27,075 & 575 & 2.17 \\
\hline 10. & $6 / 9 / 2017$ & TLKM & 4,330 & 30 & 0.7 \\
\hline
\end{tabular}

\section{DISCUSSION}

For the out of sample test of deviation percentage of price changes, in among 10 samples of stocks to be analyzed, however, the deviation percentages of price change results were still in their consistency following the MaxwellBoltzmann probability formula. The biggest deviation was on ADRO (Adaro Energy). Where, the value of percentage of price change, (or maximum deviation) was 3,75\%. From the Maxwell-Boltzmann probability calculation result above, we have the maximum deviation values of percentage of price changes were 0 to $4.67 \%$. On the other hand, the smallest deviation value of percentage of price change was on ASRI (Alam Sutra Realty) with the value of $-0.07 \%$.

Compare to previous empirical research, with the other formulae, there were no exactly data recorded for the deviation percentage of price changes in the Idx market recently. Since the Idx market is still a young financial market. So, this is also a chance to the next researchers to make a further research.

Now we arrived to discuss, whether these two formulae have accomplished and could be utilized as proxy appliances to predict the dynamic trend lines and percentage of price changes in Indonesia Stock Exchanges (Idx) market or not? As the results according to the data's, Maxwell-Boltzmann law distribution and Maxwell-Boltzmann probability formula have been proved their ability (proven) and accomplished to predict the dynamic trend lines and percentage of price changes in Idx market. Hence the Thesis hypothesis: Maxwell-Boltzmann statistic distribution law and probability formula could be utilized as proxy appliances to predict the Idx market dynamic trend lines and percentage of price changes could be accepted. 
[11] Dragulescu A., Victor M. Yakovenko, Statistical Mechanic of Money, London: Journal Eur, Phy J. B 17723 ,pp.65-73,2000. (references)

[12] Pachencov A.N, Econophysics and Financial-Economic Monitoring, Nizhniy Novgorov, (Russia): The higher school of Economics, 1990.

\section{CONCLUSION}

It can be concluded that Maxwell-Boltzmann statistic distribution law and Maxwell-Boltzmann probability formula are eligible to utilize as appliances or instruments to predict the dynamic trend lines of shares in a stock market, and percentage of price changes, particularly in Idx market. These beneficial depend on how smart one may manage and utilize these instruments. Particularly, for the weak form efficient market like in Idx has.

To obtain the results of these research, some time we have some handicaps in sample limitation. One upon a time, when we are going to find the series data needed, we faced inactivate data, and it could hapen in couple days, even for couple weeks. As the result, it would trap/confuse us to make conclusions for predicting dynamic trend line and for analizing percentage price change of a share.

It ought to be realize that in this study results, it could be influenced by the internal tradings of the decission makers of the companies, because of Idx market is a weak form efficient market. Of cource, it couldn't be avoided when there were so many insider tradings.

In the Maxwell-Boltzmann statistic, there were many parametric term could be adjust to suit to the market characteristic. Enormous area of research analysis by using Maxwell-Boltzmann statistic could be done. This research aim is not stop in here, so it is a duty for the next researcher to continue these Maxwell-Boltzmann research for predicting the financial markets trend line.

\section{REFERENCES}

[1] Abdullah, Mikrajuddin, An introduction to statistic physics for students, Bandung (Indonesia): ITB, (Bandung Institute of Technology). Bandung Vol 1 pp. 4-9, April 2007. (references).

[2] Admati, Anat R and PaulPfleiderer, A Theory of Intraday Patterns: Volume and Pric Variability, (USA): Standford University, The review of financial, Studies 1988, Vol 1, No 1.

[3] Bessembinder, Hendrik and Paul J. Seguin, Future-Trading and Stock Price Volatility, (USA): The Journal of Finance, Vol. 47, No. 5,1992 .

[4] Barber, BM, Odean T, Trading is hazardous to your wealth: The common stock investment performance of individual investors, (USA): J Finance, 55:pp. 773-806, 2000.

[5] Beiser, Arthur dan The How Liong, Modern Physics Concept, akarta (Indonesia):Erlangga Publisher, 2004.

[6] Bias, Bruno. Larry Glosten and Chester Spatt, The market Microstructure of Stock Market, (USA): Journal of Finance, 2004.

[7] Bueche, Frederick J, Introduction to physics for scientists and engineers. (USA): Mc Graw-Hill international editions, 2006

[8] Budnick, Frank S, Applied Mathematics for Business, Economics, and the Social Sciences, (USA): Mc-Graw-Hill International Edition, 2009.

[9] Caginaip, G, and M. DeSantis, Stock Price Dynamics: Nonlinear Trend, Volume, Volatility, Resistance and Money supply, Pittsburg (USA): University of Pittsburg Department of Mathematic, USA, 2008.

[10] Cambell, Benyamin A, Firm Volatility and Stock Options Incidence, California (USA): University of California Berkley, 2003.
[13] Wijaya, C, Alternative Model Analysis of Dynamic Earning Valuation and Prediction Alternative Model of Dynamic BC Error Adjusted, Jakarta(Indonesia): Doctorate Dissertation, Post Graduate Study, Faculty of Economics University of Indonesia, 2004. 